\title{
PENYALURAN BANTUAN BENCANA ALAM DAN KETERPENUHAN KEBUTUHAN KORBAN BENCANA KEBAKARAAN DI RUMAH ADAT DESA NGGELA KABUPATEN ENDE FLORES
}

\author{
Aschari Senjahari Rawe ${ }^{1)}$, Felix Welu'), Damianus Tola $^{2)}$ Antonius Ola Miten ${ }^{1)}$ \\ 1)Program Studi PGSD, FKIP, Universitas Flores, Ende, NTT, Indonesia \\ 2)Program Studi Pendidikan Ekonomi, FKIP, Universitas Flores, Ende, NTT, Indonesia \\ Corresponding author : Aschari Senjahari Rawe \\ E-mail : ascharisenjahrirawe@gmail.com
}

Diterima 16 Januari 2021, Direvisi 05 Februari 2021, Disetujui 06 Februari 2021

\begin{abstract}
ABSTRAK
Indonesia kerap menghadapi berbagai macam bencana yang datang silih berganti. Gempa bumi, tsunami, banjir, longsor, gunung meletus dan Kebakaraan kerap terjadi di Indonesia. Hal ini disebabkan oleh kondisi geografis Indonesia khususnya propinsi Nusa Tenggara Timur Kabupaten Ende yang sangat rawan bencana. Potensi bencana di Kabupaten Ende sangat besar karena kondisi geografis, geologis, hidrologis, dan demografis yang sangat berperan dalam terjadinya bencana. Tujuan dari kegiatan ini adalah bagaimana partisipasi kepedulian Mahasiswa program mata kuliah Pramuka Prodi PGSD Universitas Flores terhadap korban bencana alam kebakaran rumah adat di desa Ngelaa .Hasil kegiatan pengabdian pada masyarakat menunjukkan bahwa bagaimana perhatian dan kepedualian mahasiswa untuk membantu sesama umat manusia yang terkenah musibah bencana Alam Kebakaran Rumah Adat di Desa Ngella, Masyarakat juga mendapatkan Santun untuk keperluan mereka yang mengalami musibah,karena kepedulian Mahasiswa inisiatif untuk mengalang dana untuk mengurangi beban yang di alami masyarakat Rumah adat Desa Nggela.
\end{abstract}

Kata Kunci : penyaluran bantuan; keterpenuhan korban bencana

\begin{abstract}
Indonesia often faces various kinds of disasters that come and go. Earthquakes, tsunamis, floods, landslides, volcanic eruptions and fires often occur in Indonesia. This is due to the geographical condition of Indonesia, especially the province of East Nusa Tenggara, Ende Regency which is very prone to disasters. The potential for disaster in Ende Regency is very large because of the geographical, geological, hydrological and demographic conditions that play a big role in the occurrence of disasters. The purpose of this activity is how the participation of students in the Scout program of the PGSD Study Program at the University of Flores towards victims of natural disasters from the fire of a traditional house in Ngelaa village. The results of community service activities show that the attention and concern of students to help fellow human beings who are hit by natural disasters Fire of the Traditional House in Ngella Village, the community also gets Santun for the needs of those who experience disaster, because of the student's concern for the initiative to raise funds to reduce the burden experienced by the community of the Nggela Village traditional house.
\end{abstract}

Keywords: distribution of aid; disaster victim fulfillment

\section{PEDAHULUAN}

Terkait dengan dampak dari bencana alam, dibutuhkan penanggulangan bencana baik itu pra bencana atau (mitigasi bencana), bencana, maupun pasca bencana. Sesuai dengan UU 24/2007, Penanggulangan bencana adalah serangkaian upaya yang meliputi penetapan kebijakan pembangunan yang beresiko timbulnya bencana, kegiatan pencegahan bencana, tanggap darurat, rehabilitasi dan rekonstruksi. Ketiga upaya tersebut masing-masing memiliki fungsi dan tujuan terkait dengan penanggulangan bencana alam dan ketiga proses penanggulangan tersebut juga sangat penting dalam menghadapi bencana alam.(Purnama \& Murdiyanto, 2013).

Menurut Peraturan Pemerintah Republik Indonesa Nomor 22 Tahun 2008 tentang Pendanaan dan Pengelolaan Bantuan Bencana pasal 28 ayat (1) bahwa bantuan pemenuhan kebutuhan dasar sebagaimana dimaksud dalam pasal 24 ayat (2) huruf d, diberikan kepada korban bencana dalam bentuk penampungan sementara, bantuan pangan, sandang, air bersih dan sanitasi, dan 
pelayanan kesehatan. Bantuan darurat bencana untuk pemenuhan kebutuhan dasar korban bencana diberikan dengan memperhatikan standar minimal kebutuhan dasar dan memperhatikan prioritas kepada kelompok rentan. Agar pemberian bantuan pemenuhan kebutuhan dasar bagi korban bencana tersebut berdaya guna dan berhasil guna, perlu disusun sebuah pedoman yang berisi tentang tata cara pemberian bantuan pemenuhan kebutuhan dasar bagi korban bencana yang memenuhi standar minimal, sehingga dapat dijadikan acuan oleh pemerintah, pemerintah daerah, masyarakat nasional dan internasional, lembaga non pemerintah, baik daerah, nasional, maupun internasional.(Mappaware et al., 2020).

Masalah yang ada, dalam pelaksanaannya adalah program-program penanggulangan terkadang hanya dalam program tanggap darurat semata. Program penanggulangan bencana baik itu pra dan pasca kurang diperhatikan oleh lembagalembaga pelayanan kebencanaan. Akibatnya dampak yang terjadi akibat bencana akan lebih berat dan sulit dalam proses rehabilitasi fisik maupun rehabilitasi dari korban bencana itu sendiri.

Dengan kondisi akibat Kebakaraan sehingga warga Rumah adat Ngella,Kecamatan Wolojita Kabupaten Ende segera membutuhkan tim relawan yang dapat melakukkan penanggulangan bencana. oleh karena itu Mahasiswa/l Pendidikan Guru sekolah dasar Universitas Flores, yang mengikuti mata kuliah Pramuka selanjutnya disebut relawan adalah seorang atau sekelompok orang yang memiliki kemampuan dan kepedulian untuk bekerja secara sukarela dan ikhlas dalam upaya penaggualangan bencana.Dibentuknya Tim Relawan ini di harapkan dapat membantu korban Kebakaraan dalam segi penyaluran donasi dan juga beberapa kebutuhan yang diperlukan bagi korban Kebakaraan yang diketahui membutuhkan banyak bantuan berupa air bersih, obat-obatan, masakan siap saji, tenda atau terpal, peralatan memasak, beras dan lauk pauk, pakaian layak pakai, selimut serta kebutuhan kelompok rentan .

Tim relawan yang dibentuk oleh Mahasiswa/I melalui organisasi pramuka PGSD Universitas Flores, maka dapat membentuk karakter dan mengembangkan kemampuan dalam dirinya,Namun, untuk sampai pada tingkat pengembangan kemampuan dan membentuk karakter yang baik, perlu usaha keras yang melibatkan tidak hanya peserta yang bersangkutan namun juga pihak lain, untuk mencapainya Anggota Pramuka yang tanggu adalah organisasi eksternal non-politik, non-profit dan anggotanya adalah mahasiswa Pendidikan Guru Sekolah Dasar Universitas bertanggung jawab dalam pengembangan diri dan pembentukan karakter yang baik bagi anggotanya yang sesuai dengan filosofi Tri Program Perguruan Tinggi sendiri, Friendship, dan Religious. Keinginan untuk menolong sesama dan mempunyai rasa empati adalah modal utama menjadi relawan. Bencana bisa menimpa siapa saja dan menempatkan diri pada kondisi korban bencana juga bisa menjadi motivasi menolong.Altruisme merupakan suatu bentuk khusus dari menolong yang dengan sukarela mengeluarkan biaya dan tenaga serta dimotivasi oleh keinginan untuk meningkatkan kesejahteraan orang lain dan lebih dari sekedar mendapat reward eksternal. Untuk itu anggota Pramuka berupaya untuk meningkatkan kemampuan untuk beradaptasi dan dapat memberikan kemampuan terbaik dalam menjadi tim relawan yang juga dapat melakukkan pengembangan diri.

Hasil dari Pengbadian Masyarakat menunjukkan bahwa penyaluran bantuan korban bencana alam dapat berjalan dengan lancar, berkat dukungan dari berbagai pihak yang telah terjalin cukup solid, baik pihak BPBD, , Dinas Sosial Dinas Kesehatan, kodim, kepolisian,Kabupaten Ende Tagana, distrik, kelurahan,maupun Perguruan Tinggi, peran serta Mahasiswa/l. Program Studi Pendidikan Guru sekolah Dasar Universitas Flores maupun sukarelawan. Faktor penghambat dalam memberikan pelayanan bantuan kebutuhan korban bencana alam adalah terbatasnya alat transportasi (darat dan air), sehingga seringkali pemberian bantuan mengalami keterlambatan sampai di daerah korban bencana. Penyaluran bantuan korban bencana alam sebagian besar sudah dapat terpenuhi, seperti kebutuhan hidup korban (tanggap darurat), pelayanan kesehatan, rehabilitasi tempat tinggal, rehabilitasi lingkungan, dan rehabilitasi kerja dan usaha, walaupun ada sebagian kecil yang belum dapat terealisir karena keterbatasan dana bantuan,

seperti Alat Tenun Sarung Tradisional dan Alat Pertania dan Perkebunaan yang biasanya dipakai sebagai sarana memperoleh penghasilan untuk mencukupi kebutuhan

Mengacu pada permasalahan diatas, maka peran Perguruan Tinggi sangat dibutuhkan untuk mendukung Pemerintah dalam penangggulangan bencana baik Prabencana, saat Bencana maupun

Pasca untuk bersinergi dengan instansi terkait Padahal tahap pra bencana dan pasca bencana juga sangat penting dalam 
penanggulangan bencana alam.dengan Tri Darma Program Perguruan Tinggi Pengabdian Masyarakat Oleh karena itu Para Dosen dan Mahasiswa Progrma studi Pendidikan Guru sekolah Dasar,Universitas Flores, terketuk hatinya untuk mengalang dana, untuk para korban bencana kebakaraan di rumah Adat Desa Nggela yang merupakan salah satu destinasi budaya rumah adat Kabupaten Ende Lio. (Yuda Ery Kaswara, 2020).

\section{METODE}

Kegiatan pengabdian ini diikuti oleh Mahasiswa Mata Kuliah Kepramukaan Program Studi Pendidikan Guru Sekolah Dasar Universitas Flores angkatan 2018 sebanyak 148 Orang Pelaksanaan kegiatan "Penyaluraan Donasi Untuk Bencana kebakaraan rumah adat di desa Ngella Kecamataan Wolojita Kabupaten Ende Flores NTT. Dengan tahapan sebagai berikut : 1.Tahap Pertama Perencanaan mencari Dana Dalam kegiaatan pengabdian masyarakat Peduli Bencana, kelompok Mata Kuliah Kepramukaan,Mahasiswa Program studi Pendidikan Guru sekolah Dasar,(Putranti \& Subagya, 2005) mendengar dan membaca berita, kemudian melakukan inisiatif Diskusi bersama untuk melakukan mengalian dana dan menyiapkan apa saja keperluan untuk korban bencana kebakaran rumah adat Desa Nggela Kecamatan wolojita.(Rinawati, Dyah Ika, Diana P.Sari, Fuzie P., 2018)

2. Tahan Kedua Pembelian

Kebutuhan Korban Kebakaraan

Bantuan kebutuhan kehidupan korban bencana yang berupa makanan, minuman, dan sandang. Di samping itu mereka juga memperoleh bantuan yang berupa sembako yang sangat mereka butuhkan untuk mempertahankan hidup seperti: beras, minyak, telur, sarden, garam, susu, kecap, mie, dan lauk. Agar mereka dapat mengolah makanan dan minuman tersebut,(Prastyowati, 2013) maka juga dibantu peralatan dapur seperti: ceret, wajan, panci, termos, dan lain sebagainya.

Dalam penyaluran bantuan korban ini tidak hanya bagi para korban saja, namun diperuntukan bagi seluruh warga kampung korban yang bersangkutan secara merata,sehingga tanpa perkecualian baik bagi korban maupun bukan korban, karena kalau tidak dapat menimbulkan rasa iri hati pada sesama warga kampung.

3. Tahap Ketiga Penyaluran Bantuan Bencana Kebakaraan Rumah Adat Desa Nggela

bantuan logistik harus tepat waktu, lokasi, sasaran, kualitas, kuantitas, dan sesuai kebutuhan. Salah satu masalah yang muncul ketika terjadi bencana alam adalah kurangnya koordinasi antara para donatur dengan badan penanggulangan bencana dalam hal pendistribusian bantuan logistik. Dengan ini kami para dosen dan mahasiswa Program Studi Pendidikan Sekolah Dasar Universitas Flores, terketuk hati untuk berinisiatif untuk melakukan koordinasi untuk membagikan kebutuhan untuk para musiba,tepat sasaran sehingga bantuan di butuhkan oleh korban kebakaran di desa Nggela Kecamatan Wolojita Kabupaten Ende Flores NTT.

4. Tahap Keempat Terpenuhan

Kebutuhan Korban

Mekanisme penyaluran bantuan logistik dan peralatan kepada para korban dilakukan dengan mekanisme sebagai berikut. Penerimaan, bantuan logistik dan peralatan, Bantuan logistic merupakan sumber daya utama yang dibutuhkan setelah terjadi bencana seperti bantuan sandang dan pangan, proses administrasi harus dilakukan dengan tujuan agar bantuan menjadi tepat sasaran,dan harus dibagikan secara langsung.sehingga tepat sasaran yang di tujukan oleh Korban yang di butuhkan.

\section{HASIL DAN PEMBAHASAN}

\section{Tahap Pertama Perencaanaan Mencari dana Untuk Bencana Kebakaraan di Desa Nggela}

Perencaan awal inisiatif dari dosen dan mahasiswa program studi PGSD mata kuliah Kepramukaan. Melihat berita informasi dari masyarakat setempat dan media masa yang merilis adanya kebakaran Rumah adat Desa Ngelaa,maka dengan ide dan gagasan Mahasiswa untuk mencari dana kemanusian,untuk membantu korban kebakaraan yang terjadi di rumah adat desa a Ngella kecamataan Wolojita Kabupaten Ende Nusa Tenggara timur.agar kebutuhan akan masalah penyaluraan atau donasi tepat pada sasaran dan tujuan masyarakat, sehingga terpenuhi,

(Pretty A. Langkun, Ventje llat, 2019)

\section{Tahan Kedua Pembelian \\ Kebutuhan Korban Kebakaraan}

Bencana yang disebabkan faktor alam maupun faktor manusia,dampaknya telah banyak menimbulkan korban jiwa, kerugian harta benda dan rusaknya sarana dan prasarana publik serta dampak psikologis, dalam keadaan tertentu dapat menghambat pembangunan nasional. Penundaan terhadap respon darurat khususnya distribusi bantuan logistik yang tidak tepat waktu dapat 
menimbulkan dampak yang buruk bagi korban bencana. Bantuan logistic merupakan sumber daya utama yang dibutuhkan setelah terjadi bencana seperti bantuan sandang dan pangan, oleh karena itu mahasiswa membeli kebutuhan koraban bencana kebakaraan berupa,sembako Beras $250 \mathrm{Kg}$, Supermi 20 dos,Sabun dan Alat Tulis Sekolah,Pinsil,Pulpen dan Buku.(Lanni, 2019).

\section{Tahap Ketiga Penyaluran Bantuan Bencana Kebakaraan Kampung Rumah Adat Desa Ngela}

bantuan logistic sangat dibutuhkan pada saat terjadi bencana. Dukungan bantuan logistik harus tepat waktu, lokasi, sasaran, kualitas, kuantitas, dan sesuai kebutuhan. Salah satu masalah yang muncul ketika terjadi bencana alam adalah kurangnya koordinasi antara para donatur dengan badan penanggulangan bencana dalam hal pendistribusian bantuan logistik. Beberapa donatur dari instansi atau perusahaan melakukan pemberian bantuan secara langsung kepada korban di lokasi bencana. Hal ini dapat menyebabkan ketidak merataan distribusi bantuan. Algoritma first-fit dapat diimplementasikan pada sistem pendistribusian materi bantuan yaitu, akan mengalokasikan materi bantuan ke posko-posko pengungsian dengan tepat. Maka dengan ini mahasiswa Program Studi Pendidikan Guru Sekolah Dasar Universitas Flores, secara langsung turun ke lokasi kebakaraan untuk menyerahkan bantuan dan kebutuhan seperti sembakao,alat tulis menulis dan keperluan lain yang di butuhkan. (Makmum \& Sadat, 2019)

\section{Tahap Keempat Terpenuhan Kebutuhan Korban}

Mekanisme penyaluran bantuan logistik dan peralatan kepada para korban dilakukan dengan mekanisme sebagai berikut. Penerimaan, bantuan logistik dan peralatan dari Mahasiswa Program studi Pendidikan Guru Sekolah dasar Universitas Flores diterima dan dijemput oleh mahasiswa, Kemudian mengantar bantuan, yaitu pada Posko yang beradaan di kantor desa.,(Kiswantoro et al., 2020) untuk di serahkan ke kepala desa, kemudian kepala desa dan Mahasiswa membagikan bantuan sembako dan alat tulis kepada msayarakat sesuai dengan data penerima musiba kebakaran dan kebutuhan korban kebakaraan Posko kedatangan dilaksanakan administrasinya untuk ditindaklanjuti sesuai dengan mekanisme pengelolaannya. Dari hasil penelusuran kasus diketahui bahwa proses administrasi harus dilakukan dengan tujuan agar bantuan menjadi tepat sasaran, sesuai yang dengan prosedur yang pada tepat pada sasaran yang di tujukan..(M.Rifansyah Praja Pratama, 2020)

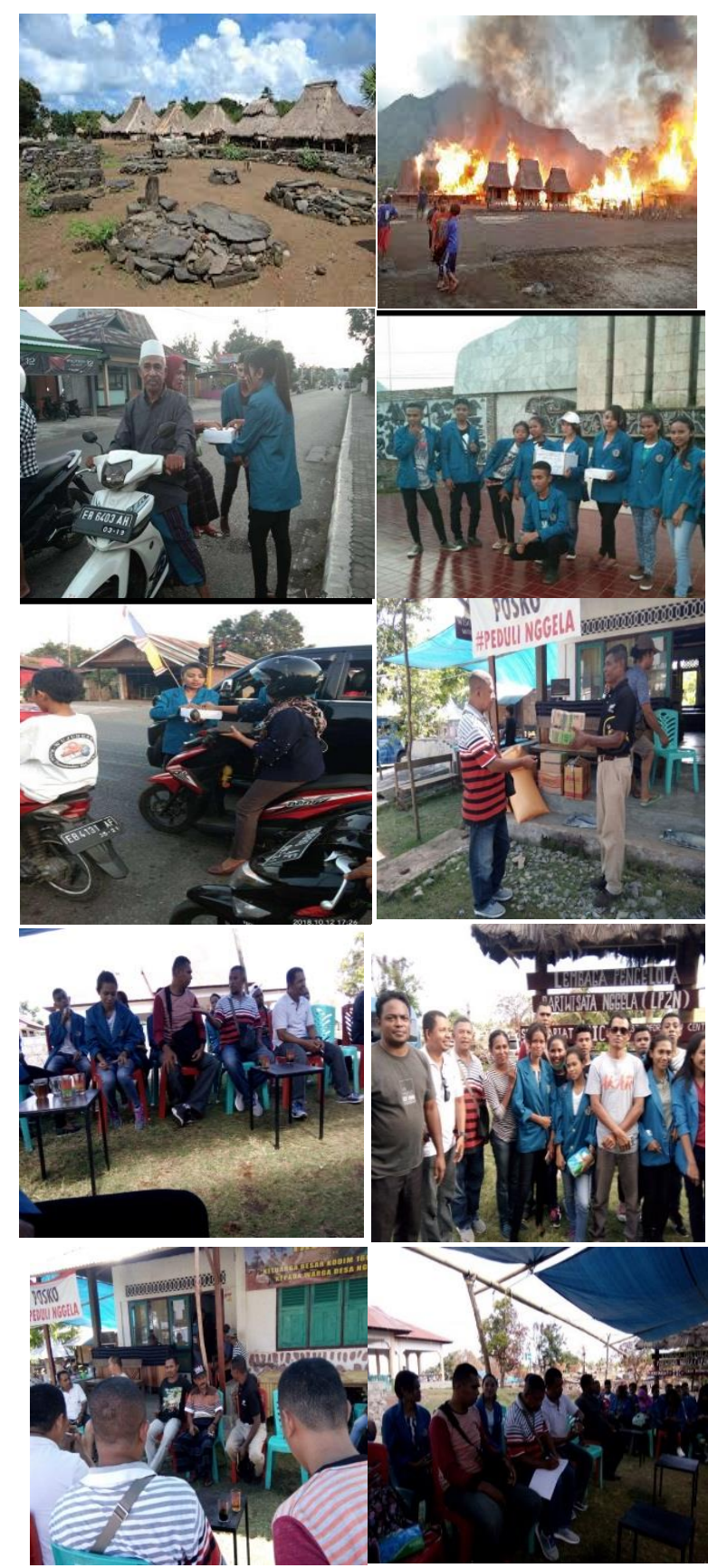

Gambar 1. Mengisi Buku Tamu kedatangan Para Dosen dan Mahasiswa di Posko Bantuan Masyarakat Kampung Desa Rumah Adat Nggela 


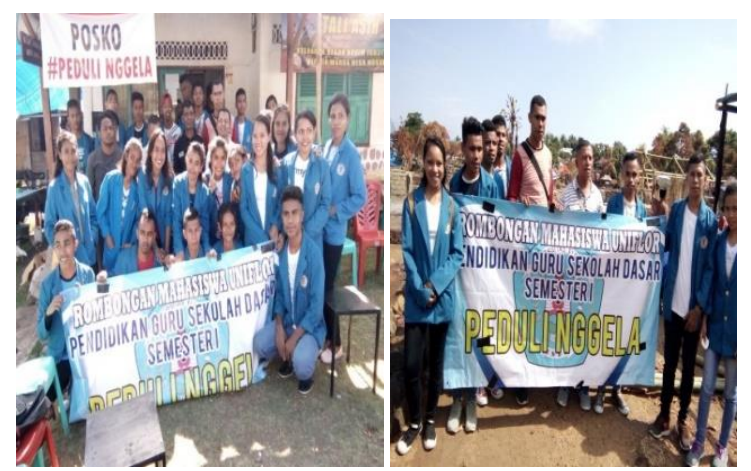

Gambar 2. Penyerahan Sembakao dan Kelengkapan Alat Tulis kepada Kepala Desa Nggela selanjutnya diserahkan kepda masyarakat korban Bencana Kebakaraan Rumah Adat

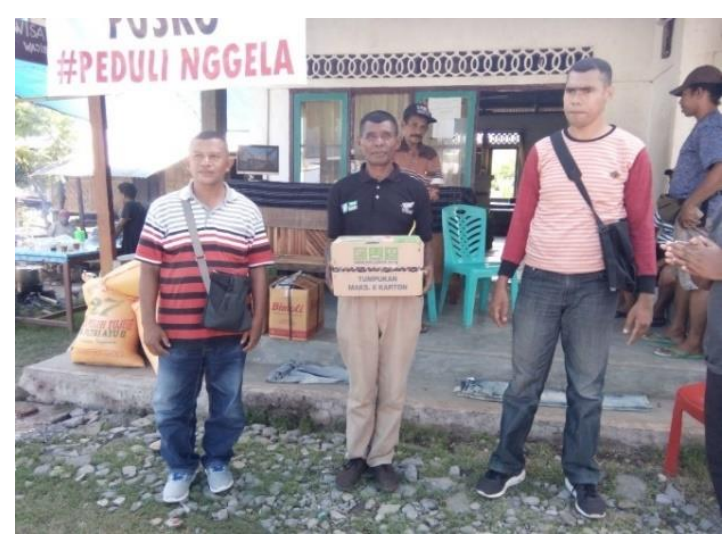

Gambar 3 Selesai penyerahaan dan pembagian kepada Masyarakat musiba Kebakaraan Rumah Adat Desa Nggela

\section{SIMPULAN DAN SARAN}

Berdasarkan hasil pengabdian yang dilakukan di Kampung Adat Desa Ngella Kecamatan Wolojita, penyaluran bantuan bencana kebakaraan rumah adat yang merupakan destinasi wisata dan juga rumah adat untuk upacara Ritual dapat terpenuhan kebutuhan korban yang diperoleh dari wawancara, observasi, serta analisis lapangan dapat disimpulkan. Sehingga pola lama yang dilakukan oleh pihak pemerintah dan pihak sukarelawaa,menyerahkan bantuan tida tepat sasan.sehinggan ini inisiatif dari pihak mahasiswa membuat, Sistem penyaluran bantuan yang pada saat ini mampu mencapai tujuannya. yaitu keterpenuhan bantuan sembakao dan alat tulis Sekolah pada sasaran yang di tujukan kepada korban kebakaraan di Kampung Adat desa nggela Kecamatan Wolojita Kabupaten Ende Propinsi Nusa Tenggara Timur.

\section{UCAPAN TERIMA KASIH}

Tim pengabdian masyarakat,Mata Kuliah Kepramukaan mengucapkan terima kasih kepada kepala Desa Nggela, ketua RW,aparat desa, dan anggota Anak Cinta Lingkungan, Desa Wisata Rumah Adat, Kecamatan Wolojita, Kabupaten Ende. Kerjasama dosen PGSD Universitas Flores, Ketua Yayasan dan Rektor Universitas Flores yang telah terjalin hingga terselenggranya kegiatan pengabdian masyarakat ini.

\section{DAFTAR RUJUKAN}

Kiswantoro, A., Rohman, H., \& Susanto, D. R. (2020). Penyaluran Alat Pencegahan dan Sosialisasi Protokoler Kesehatan untuk Pelayanan Kunjungan Wisatawan dalam Menghadapi New Normal Pasca Pandemi Covid-19. Jurnal Abdimas Pariwisata, 1(2), 3851.

Lanni, F. (2019). Bencana Di Indonesia Role of Academic Institution in Disaster. Pendekatan Multidisiplin IImu Dalam Menejemen Bencana, 1-5.

M.Rifansyah Praja Pratama, A. G. (2020). Penerapan Metode Algoritma First-Fit Dalam Pendistribusian Bantuan Bencana Di Badan Penanggulangan Bencana Daerah (BPBD) Kota Sukabumi. Indonesian Journal on Networking and Security, 9(4), 42-50.

Makmum, M., \& Sadat, M. A. (2019). Implementasi Program Penyaluran NUCare LAZISNU Jombang Terhadap Pemberdayaan Masyarakat. Jurnal Hukum Keluarga Islam, 4(2), 166-184.

Mappaware, N. A., Tanra, A. H., Wahid, S., Rijal, S., Muchsin, A. H., Makmun, A., Masdipa, A., Yaqien, K., Haq, P., Ramadani, F. A., Fadhilah, Y., Fajrin, N., Rahmat, A., Suci, H., Fitrah, A. A., \& Haq, M. S. (2020). Tim Relawan Association of Medical Doctor of Asian ( AMDA ) Indonesia dan Asian Medical Students Association ( AMSA ) UMI pada Banjir Bandang Masamba Sulawesi Selatan. Jurnal Pengabdian Kedokteran Indonesia, 1(1), 30-38.

Prastyowati, S. (2013). Sistem Penyaluran Bantuan Bencana Alam dan Keterpenuhan Kebutuhan Korban Kasus di Kabupaten Padang Pariaman. Jurnal PKS, 12(1), 80-92.

Pretty A. Langkun, Ventje llat, R. J. P. (2019). 3 1,2,3. Jurnal Riset Akuntansi Going Concern, 14(1), 54-57.

Purnama, A., \& Murdiyanto. (2013). Penyaluran Bantuan Korban Bencana Alam Studi Kasus Pemulihan Kehidupan Korban Bencana Alam di Kota Jayapura. Jurnal PKS, 12(2), 183-196.

Putranti, B. D., \& Subagya, Y. T. (2005). Jerit Bantuan, Jerit Pengungsi. 
Rinawati, Dyah Ika, Diana P.Sari, Fuzie P., F. (2018). Rancang Bangun Sistem Informasi Bantuan Logistik Bencana Studi Kasus Pada Bpbd Kabupaten Magelang. J@ti Undip: Jurnal Teknik Industri, 13(1), 51-60. https://doi.org/10.14710/jati.13.1.51-60

Yuda Ery Kaswara. (2020). EFEKTIVITAS ORGANISASI TARUNA SIAGA BENCANA ( TAGANA ) DALAM MENANGGULANGI BENCANA KEBAKARAN PERMUKIMAN PENDUDUK. E.Journal .IpfispUnmul.Ac.ld, 8(1), 219-232. 